\title{
Article
}

\section{Design, Development and Evaluation of Thermal Properties of Polysulphone-CNT/GNP Nanocomposites}

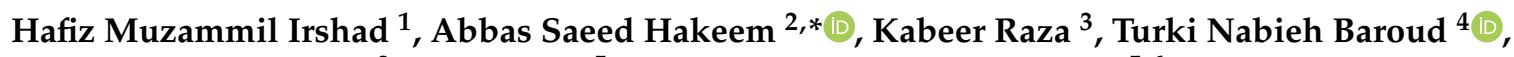 \\ Muhammad Ali Ehsan ${ }^{2}$, Sameer Ali ${ }^{5}$ and Muhammad Suleman Tahir ${ }^{5,6}$ \\ 1 Faculty of Materials and Chemical Engineering, GIK Institute of Engineering Sciences and Technology, \\ Topi 23460, Khyber Pakhtunkhwa, Pakistan; muzammil@giki.edu.pk \\ 2 Interdisciplinary Research Center for Hydrogen \& Energy Storage (IRC-HES), King Fahd University of \\ Petroleum \& Minerals, Dhahran 31261, Saudi Arabia; meali@kfupm.edu.sa \\ 3 Department of Mechanical Engineering, Khwaja Fareed University of Engineering \& Information \\ Technology (KFUEIT), Rahim Yar Khan 64200, Punjab, Pakistan; kabeer.raza@kfueit.edu.pk \\ 4 Mechanical Engineering Department, King Fahd University of Petroleum and Minerals (KFUPM), \\ Dhahran 31261, Saudi Arabia; turkibaroud@kfupm.edu.sa \\ 5 Department of Chemical Engineering, University of Gujrat, Gujrat 50700, Punjab, Pakistan; \\ sameeralihakeem1@gmail.com (S.A.); vc@kfueit.edu.pk (M.S.T.) \\ 6 Department of Chemical Engineering, Khwaja Fareed University of Engineering \& Information \\ Technology (KFUEIT), Rahim Yar Khan 64200, Punjab, Pakistan \\ * Correspondence: ashakeem@kfupm.edu.sa
}

check for updates

Citation: Irshad, H.M.; Hakeem, A.S.; Raza, K.; Baroud, T.N.; Ehsan, M.A.; Ali, S.; Tahir, M.S. Design, Development and Evaluation of Thermal Properties of Polysulphone-CNT/GNP

Nanocomposites. Nanomaterials 2021, 11, 2080. https://doi.org/10.3390/ nano11082080

Academic Editor: Alberto Fina

Received: 28 July 2021

Accepted: 13 August 2021

Published: 16 August 2021

Publisher's Note: MDPI stays neutral with regard to jurisdictional claims in published maps and institutional affiliations.

Copyright: (c) 2021 by the authors. Licensee MDPI, Basel, Switzerland. This article is an open access article distributed under the terms and conditions of the Creative Commons Attribution (CC BY) license (https:// creativecommons.org/licenses/by/ $4.0 /)$.
Abstract: Polysulphone (PSU) composites with carbon nanotubes (PSU-CNT) and graphene nanoplatelets (PSU-GNP) were developed through the solution casting process, using various weight load percentages of $1,3,5$, and $10 \mathrm{wt} \%$ of CNT and GNP nanofillers. The microstructural and thermal properties of the PSU-based composites were compared. The microstructural characterisation of both composites (PSUCNTs and PSU-GNPs) showed a strong matrix-filler interfacial interaction and uniform dispersion of CNTs and GNPs in the PSU matrix. The analysis demonstrated that both the thermal conductivity and effusivity improved with the increase in the weight percentage ( $w t \%)$ of CNTs and GNPs because of the percolation effect. The polysulphone-based composite containing $10 \mathrm{wt} \% \mathrm{CNTs}$ showed a remarkably high thermal conductivity value of $1.13(\mathrm{~W} / \mathrm{m} \cdot \mathrm{K})$, which is $163 \%$ times higher than pure PSU. While the glass transition temperature $(\mathrm{Tg})$ was shifted to a higher temperature, the thermal expansion was reduced in all the PSU-CNT and PSU-GNP composites. Interestingly, the CNTs allowed homogeneous distribution and a reasonably good interfacial network of interaction with the PSU matrix, leading to better microstructural characteristics and thermal properties than those of the PSU-GNP composites. The findings highlight the importance of controlling the nature, distribution, and content of fillers within the polymeric matrix.

Keywords: polysulphone; carbon nanotube; graphene platelet; thermal properties; nanocomposite

\section{Introduction}

Polymer materials have several advantages over metallic materials, such as high corrosion resistance, light weight, low cost, ease of processing, and chemical stability. However, there are obstacles in overcoming the high thermal expansion, low thermal conductivity, poor mechanical strength, and lower service temperature range [1]. The mismatch in thermal expansion between metallic and polymeric components is the primary cause of failure in polymer-metal joints and adhered surfaces [2]. Neat polymers usually exhibit thermal conductivity in the range of 0.1 to $0.4 \mathrm{~W} / \mathrm{m} \cdot \mathrm{K}$ [3]. In contrast, most metals possess high thermal conductivity $(100-400 \mathrm{~W} / \mathrm{m} \cdot \mathrm{K})$ [4].

Nanocomposites are multiphase solid materials and have one phase that is less than $100 \mathrm{~nm}$ in size. Nanosized particles with a high aspect ratio allow strong particle-particle interactions and lead to efficient heat energy flow. However, the ultrahigh interfacial area of 
the nanosized fillers permits a strong matrix-to-filler interaction at the level of the interface with the polymer matrix for the efficient transmission of thermal energy. This further strengthens the mechanical and thermal properties of the material [5]. Polysulphone is an amorphous polymer with a maximum continuous use temperature of $190{ }^{\circ} \mathrm{C}$, and it can maintain its mechanical properties for an extended period of time [6]. It is utilised in membranes because of its good thermal stability and strength [7]. Polysulphone (PSU) is typically used in food processing equipment, bioreactor membranes, fuel cell membranes, and aviation and electronic components [8]. The polysulphone-hydroxyapatite (PSU+HAp) composite is biostable and can be utilised for orthopaedic applications [9]. Polymer nanocomposites filled with thermally conductive fillers such as aluminium nitride [10], CNTs, and graphene can be used to encapsulate electronic devices (photovoltaic systems) to protect them from adverse environments (i.e., high temperatures or corrosive), improve their performance, and extend their reliability [11-16]. Considerable research is being conducted to develop polymer nanocomposites with improved thermal properties and lifetime behaviour in the heating, ventilation, air conditioning, and refrigeration (HVAC and R) environment; computer chips; electronic packaging; LED systems, and many other conventional and advanced applications [17-19] Thermal conductivity is a bulk property of polymer nanocomposites. The principal factors that affect thermal conductivity are the filler concentration, the thermal conductivity of the filler, particle size, and interfacial thermal resistance [20]. Superior thermal properties can be obtained using suitable metallic, nitride, and oxide fillers such as aluminium nitride, cubic boron nitride, hexagonal boron nitride [21], strontium ferrite, magnetite, barite, and copper [22]. $\mathrm{TiO}_{2}$ addition (1-2 wt\%) in PSU provides high thermal stability, and $40 \mathrm{vol} \%$ hexagonal boron nitride provides ideal thermal stability with thermal conductivity of $1.1 \mathrm{~W} / \mathrm{m} \cdot \mathrm{K}$ [23]. The thermal conductivity increases from 0.22 to $0.93 \mathrm{~W} / \mathrm{m} \cdot \mathrm{K}$ upon the addition of $44 \mathrm{vol} \%$ of magnetite $\left(\mathrm{Fe}_{3} \mathrm{O}_{4}\right)$ [24]. Zhao et al. produced hybrid composites of graphene foam with carbon fibre (CF)-reinforced polydimethylsiloxane (PDMS) via solution mixing and high-speed shear mixing techniques. They showed that PDMS filled with $10 \mathrm{wt} \% \mathrm{CF}$ infiltrated into graphene foam could provide a bulk thermal conductivity of $0.55 \mathrm{~W} / \mathrm{m} \cdot \mathrm{K}$. The effect of carbon fibre on the thermal properties of the graphene polymer composite showed that with $10 \mathrm{wt} \% \mathrm{CF}$, the maximum thermal conductivity reached was $0.55 \mathrm{~W} / \mathrm{m} \cdot \mathrm{K}$ [25]. Yang et al. developed epoxy-based hybrid nanocomposites by introducing CNTs and GNPs through a solution casting route. The mixing of high- and low-aspect-ratio fillers resulted in a synergistic enhancement of the thermal and mechanical properties [26]. Similarly, a synergistic improvement in thermal conductivity of $0.86 \mathrm{~W} / \mathrm{m} \cdot \mathrm{K}$ with the addition of $10 \mathrm{wt} \% \mathrm{CNT}$ with $\mathrm{Al}_{2} \mathrm{O}_{3}$ in the PDMS matrix has been reported [27].

A high coefficient of thermal expansion (CTE) is a limiting factor in the utilisation of polymers. The most common thermoplastics used in polymer composite industries have thermal expansion in the range of 25-200 ppm/K [28], which can be adjusted to lower expansion values by incorporating fillers with a negative (or lower) coefficient of thermal expansion. It is possible to attain a material with approximately zero thermal expansion combined with positive and negative expanding materials for various applications [29]. Graphene and CNTs at room temperature $\left(25^{\circ} \mathrm{C}\right)$ have a negative coefficient of thermal expansion, so they can be added to polymer matrices to lower the thermal expansion for polymer composites effectively; however, the coefficient of thermal expansion is not affected by the addition of less than $0.5 \mathrm{wt} \%$ of CNTs and GNP [30]. Conductive polymer composites composed of carbon nanotubes and graphene have been examined for use in strain-sensing devices [31].

At room temperature $\left(25^{\circ} \mathrm{C}\right)$, the observed thermal conductivity of MWNTs is more than $3000 \mathrm{~W} / \mathrm{m} \cdot \mathrm{K}$ and that of single-layer graphene is approximately $5000 \mathrm{~W} / \mathrm{m} \cdot \mathrm{K}$ [32], owing to its very high phonon mean free path [33]. Carbon nanotube (CNT) addition in a polymer matrix leads to improved percolation at lower loading and such composites have a good estimation of the thermal properties using different models [34]. However, a higher filler loading on the nanoscale is likely to agglomerate and reduce the aspect ratio and 
effective surface-area-to-volume ratio [35]. The number of interaction points (between the fillers and the polymer matrix) in the percolation network was enhanced by the addition of nanosized fillers [36]. There are issues related to the effective dispersion of CNTs in the polymer matrix - that is, accumulation, the limited availability of high-quality CNTs, and their production cost [37]. Therefore, graphene sheets offer another option for producing nanocomposites filled with graphene because of their abundant graphite precursors [38]. Graphene with ultra-high thermal conductivity is a promising material for distributing heat generated in microelectronics [39]; with shallow filler content, it can significantly improve the thermal properties [40].

The thermal properties of similar filler materials vary drastically in various polymer matrices, and a comparison of multiple materials is difficult [24]. For many polymer composite materials, further research is required to probe the essential thermal property data, including the thermal conductivity, maximum operating temperature, and coefficient of thermal expansion. Nanofillers can enhance the ultra-low thermal conductivities of polymers with a super-high thermal conductivity of approximately $1000 \mathrm{~W} / \mathrm{m} \cdot \mathrm{K}$ at room temperature $\left(25^{\circ} \mathrm{C}\right)[41]$.

In this study, GNPs and CNTs were systematically added into the PSU matrix via a solution mixing process to design polymer nanocomposites with improved thermal properties. The precursors and final composite materials were characterised in terms of X-ray diffraction, microstructures, Raman scattering, thermal conductivity, thermal expansion, and the glass transition temperature.

\section{Materials and Methods}

The matrix PSU was procured from Sigma-Aldrich (USA), the CNTs from Cheap Tubes (USA), and GNPs from Graphene Supermarket (USA). The GNPs were composed of 30 to 50 monolayers, with average thickness in the range of $12 \mathrm{~nm}$ and an average lateral size of $\sim 3 \mu \mathrm{m}$. The matrix and reinforcement compositions in wt $\%$ are shown in Table 1 , along with their digital illustrations, along with Table 1.

Table 1. Compositional variation of PSU and reinforcements (CNT/GNP).



\begin{tabular}{cccccccccc}
\hline \multicolumn{10}{c}{ Composition } \\
\hline Sample IDs & $\mathbf{1}$ & $\mathbf{2}$ & $\mathbf{3}$ & $\mathbf{4}$ & $\mathbf{5}$ & $\mathbf{6}$ & $\mathbf{7}$ & $\mathbf{8}$ & $\mathbf{9}$ \\
\hline Composition (\%) & Pure PSU & $1 \%$ CNT & $3 \%$ CNT & $5 \%$ CNT & $10 \%$ CNT & $1 \%$ GNP & $3 \%$ GNP & $5 \%$ GNP & $10 \%$ GNP \\
PSU (gm) & 10 & 9.9 & 9.7 & 9.6 & 9 & 9.9 & 9.7 & 9.6 & 9 \\
CNTs/GNPs (gm) & 0 & 0.1 & 0.3 & 0.4 & 1 & 0.1 & 0.3 & 0.4 & 1 \\
\hline
\end{tabular}

The nanocomposites were processed using the solution casting method [42]. Initially, specific amounts of CNTs and GNPs were added to $10 \mathrm{~mL}$ of N-Methyl-2-pyrrolidone (NMP). The mixture was sonicated for $2 \mathrm{~h}$ using a probe sonicator (Model VC 750, Sonics, Newtown, CT, USA) to obtain a stable suspension of the different compositions as indicated in Table 1. After the preparation of the solution, the required amount of PSU was dissolved in $10 \mathrm{~mL}$ of NMP in a separate container by magnetic stirring for a further $2 \mathrm{~h}$. The mixtures were then mixed and stirred over a magnetic hot plate for another $12 \mathrm{~h}$. $\mathrm{N}$ - 
Methyl-2-pyrrolidone (NMP) was used as a solvent to dissolve PSU into a suspension with different weight percentages $(0,1,3,5$, and $10 \mathrm{wt} \%)$ of reinforcements (CNTs/GNPs). The stirring of the mixture was continued for $12 \mathrm{~h}$ using a magnetic stirrer to obtain a fully homogenised mixture.

The homogenised solution was cast in a petri dish and kept in a vacuum oven for $24 \mathrm{~h}$ at $80{ }^{\circ} \mathrm{C}$ to evaporate the solvent completely. Upon drying, the developed nanocomposite film was removed for necessary characterisation and evaluation of the thermal properties. The thermal conductivity and effusivity were measured at room temperature, $25^{\circ} \mathrm{C}$, using thermal analyser equipment C-Therm-TCi, (Fredericton, NB, Canada), for which the measurements were based on the modified transient plane source method. The coefficients of thermal expansion $(\alpha)$ were measured using a Mettler Toledo thermo-mechanical analyser (TMA/SDTA-LF/1100, Greifensee, Switzerland) from room temperature $\left(25^{\circ} \mathrm{C}\right)$ up to $180{ }^{\circ} \mathrm{C}$ at a heating rate of $283 \mathrm{~K} / \mathrm{min}\left(10^{\circ} \mathrm{C} / \mathrm{min}\right)$. The $\mathrm{T} g$ was evaluated as a function of the filler composition using differential scanning calorimetry (DSC) (Mettler Toledo, Greifensee, Switzerland).

The phase analysis of the composites was conducted using X-ray diffraction experiments performed using a Benchtop MiniFlex X-ray diffractometer (Rigaku, Tokyo, Japan). The XRD was operated by maintaining a tube current of $10 \mathrm{~mA}$, an accelerating voltage of $30 \mathrm{kV}$, and $\mathrm{Cu} \mathrm{K} \alpha 1$ radiation. A Raman microscope (Thermo Scientific, DXR2, Boston, MA, USA) was used to observe molecular disorientation and band characteristics with an excitation wavelength of $455 \mathrm{~nm}$ (laser power of $2.5 \mathrm{~mW}$ ), and the spectra were acquired at $25{ }^{\circ} \mathrm{C}$ between 200 and $3500 \mathrm{~cm}^{-1}$. A field emission scanning electron microscope (FESEM) from Tescan (Lyra3, Tescan, Brno, Czech Republic) was used to characterise the surface morphology of the composites at an accelerating voltage of $20 \mathrm{kV}$.

\section{Results and Discussion}

\subsection{Microstructural Characterisation}

Figure 1 presents the FESEM images of the as-received CNTs and GNPs. Figure 1a shows that as-received CNTs were entangled, constructing a percolating network in the polymer matrix. The entanglement of CNTs is viewed as a beneficial factor in constructing a stable conductive network in the polymer matrix. Figure $1 \mathrm{~b}$ shows the stacks of multilayered graphene nanoplatelets with an average thickness of approximately $12 \mathrm{~nm}$.
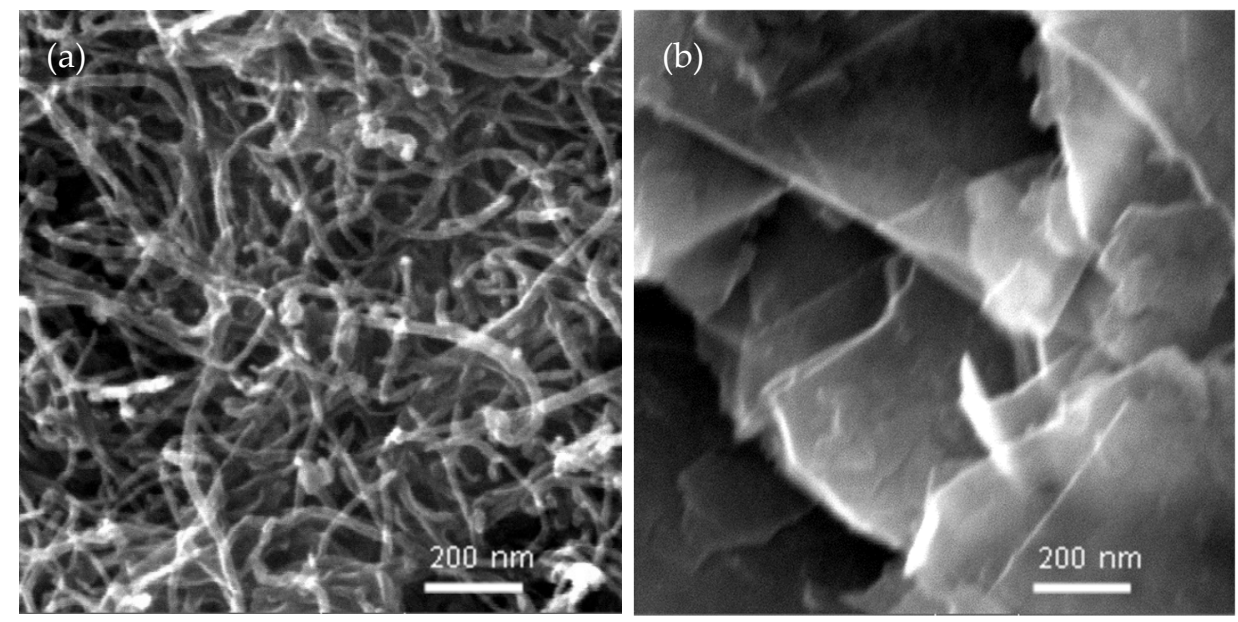

Figure 1. FESEM micrographs of pure CNTs (a) and GNPs (b).

The XRD spectra of the pristine PSU and the composite samples are shown in Figure 2. The XRD pattern of pristine PSU is free of any sharp crystalline peak, which indicates its amorphous nature and typical characteristics of transparent and thermoplastic polymers. No crystalline peaks appeared in samples S1-S4 upon adding $5 \mathrm{wt} \%$ of PSU filler into CNTs and GNPs (Table 1). Samples S8 and S9 showed sharp graphite peaks at $2 \theta=26^{\circ}$. However, 
the corresponding samples with CNT addition (S4 and S5) did not display any sharp peaks at the same diffraction angle. This observation is attributed to the more significant molecular weight of GNPs, which produced comparatively higher crystallinity in S8 and S9 samples.

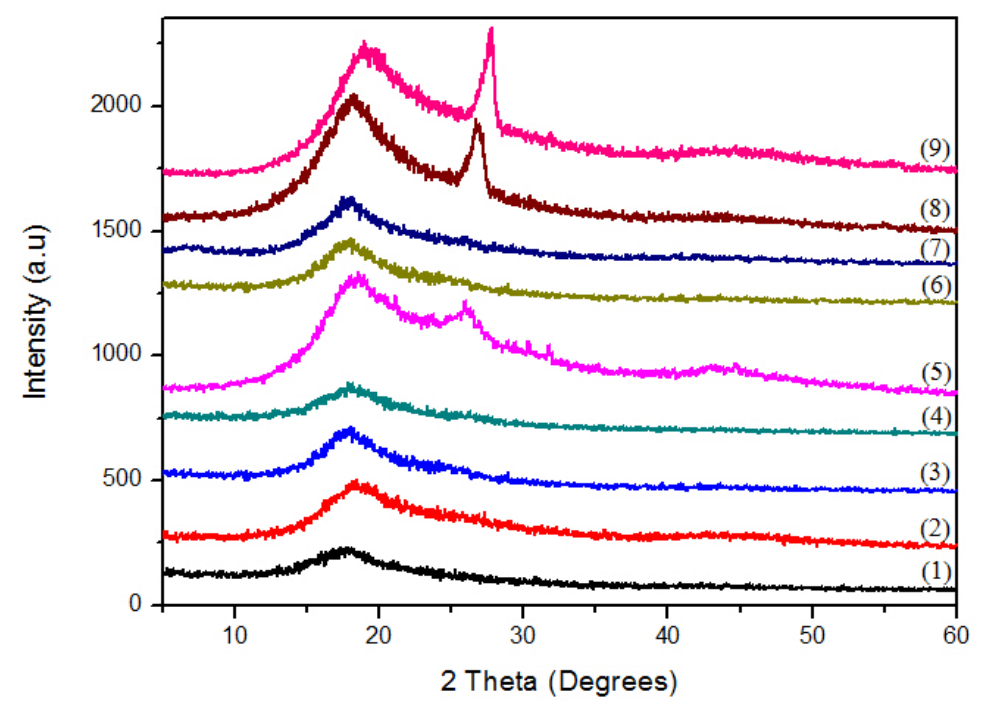

Figure 2. X-ray diffraction (XRD) patterns of PSU-CNT and PSU-GNP samples. Numbers (1)-(9) in parentheses correspond to numbers of samples for which compositions are described in Table 1.

Analysis of the XRD patterns of the pristine PSU and PSU-CNT and PSU-GNP nanocomposites (Figure 2) showed the crystallinity of the composites. The XRD pattern of pure PSU (Figure 2(1)) showed a broad diffraction peak at approximately $2 \theta=18^{\circ}$, indicating a primarily amorphous structure for PSU. In the PSU-CNT nanocomposites, there was no indication of a sharp peak, even in the presence of CNTs in the polymer matrix. Notably, when the CNT content was increased to $10 \mathrm{wt} \%$ (Figure 2(5)), a diffraction peak appeared at approximately $2 \theta=26^{\circ}$. For PSU-GNP nanocomposites, with the addition of a small amount of graphene (1-3 wt\%), the nanocomposites showed identical XRD patterns to pure PSU. However, when the graphene content was increased to 5 or $10 \mathrm{wt} \%$, a diffraction peak was observed at approximately $2 \theta=27^{\circ}$, which demonstrates the aggregation of graphene nanoplatelets, especially for the $10 \mathrm{wt} \%$ graphene (Figure 2(9)). The absence of a peak in the composites with lower concentrations confirms dispersion within the reinforcements in the matrix [43]. Peak broadening at higher concentrations (Figure 2(5),(9)) demonstrates a slight change in the polysulphone structure, which perhaps may be due to the dominant interactions of weak Van der Waals forces.

The molecular disorientation and band characteristics were observed via Raman spectroscopy. The Raman spectrum of pure PSU shows typical peaks at $790, \sim 1147$, $\sim 1583$, and $\sim 3065 \mathrm{~cm}^{-1}$. The band characteristics of PSU, CNT, and GNPS (composite) are shown in the Raman spectra in Figure 3, which shows that the D and G bands appeared at 1175 and $1650 \mathrm{~cm}^{-1}$, respectively. These are slightly shifted from the characteristic peaks (i.e., centred at 1345 and $1565 \mathrm{~cm}^{-1}$ ) of carbon nanoallotrope materials [44]. The increase in the intensity ratios of the $\mathrm{D}$ to $\mathrm{G}$ bands shows a reduction in the order (carbon atoms) as the amount of reinforcement increases. This phenomenon can be attributed to hydrogen bonding interactions between the polymer matrix chains and reinforcements [31]. 


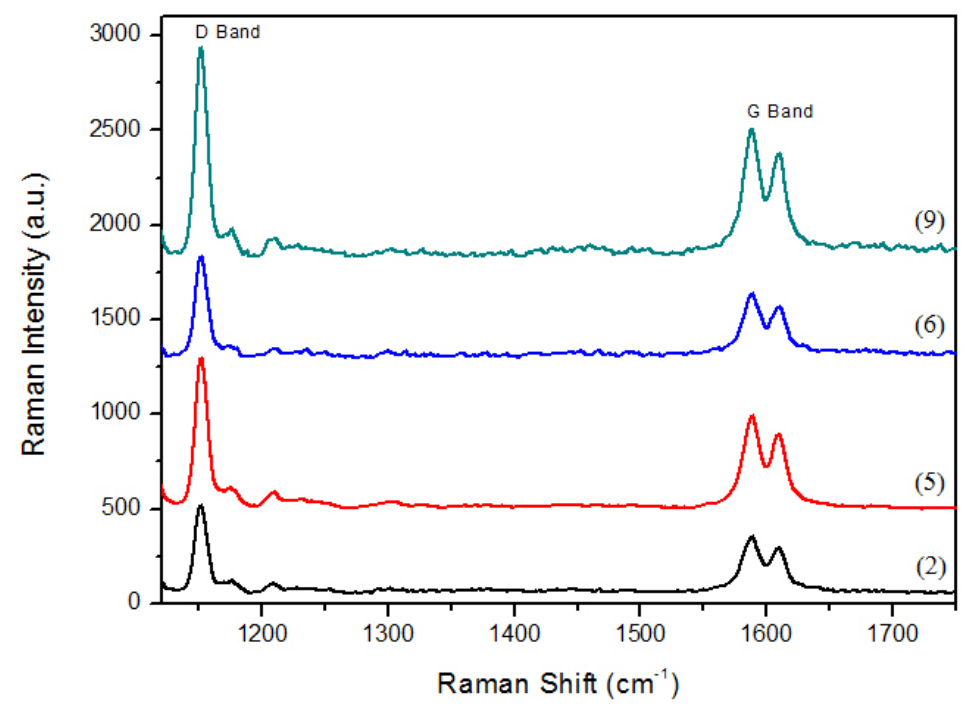

Figure 3. Raman analysis of PSU-CNT and PSU-GNP nanocomposites. Numbers (2), (5), (6), and (9) in parentheses correspond to sample IDs and compositions described in Table 1.

The $\mathrm{D}$ band peak is associated with disorder arising from the Raman scattering process in disordered carbon atoms. In contrast, the $\mathrm{G}$ band peak results from the in-plane tangential stretching of carbon-carbon bonds. However, the relative intensity ratio of ID/IG is a good indicator of disorder; a higher value of this ratio indicates a higher number of defects [45]. Therefore, the defect level can be assessed by determining the intensity ratio of the D and G band peaks (ID/IG ratio) [36]. The ID/IG ratios of the $10 \mathrm{wt} \% \mathrm{CNTs}$ and graphene polymer composites were 1.6 and 1.4, respectively, indicating that the defect level of the $10 \mathrm{wt} \%$ CNT composite was higher than that of the $10 \mathrm{wt} \%$ GNPs. The ID/IG ratio increased, confirming that the fillers were structurally intact and their concentration governed the Raman spectra of the developed nanocomposites [44]. Figure 4 shows the FESEM micrographs of the fractured surfaces of the PSU-CNT and PSU-GNP composites. The formation of a three-dimensional CNT network and interconnectivity in the PSU matrix can be observed in the FESEM images (Figure $4 \mathrm{~b}-\mathrm{i}$ ).

The developed composites possessed a larger contact area and better interaction between the CNTs, as well as improved matrix percolation and synergistic enhancement. The interfacial interaction network formation in both types of reinforcements was excellent and suitable for a conductive path with high thermal conductivity. At higher loadings $(10 \mathrm{wt} \%)$, the dispersion of CNTs is better than GNPs because intermolecular Van der Waals forces are much weaker in CNTs when compared with GNPs. It is evident from Figure $4 \mathrm{f}-\mathrm{i}$ that the GNPs were well-dispersed in the matrix at lower concentrations, showing good compatibility when compared with higher concentrations. Hence, it was observed that the CNTs had better and easier dispersion in the PSU matrix than the GNPs.

The PSU-GNP composite with $10 \mathrm{wt} \%$ of GNP was closely combined and stacked, leading to the aggregation of graphene, as shown in Figure 4i, which was also confirmed by the XRD peak at $2 \theta=27^{\circ}$. The strong surface-surface attraction between the filler sheets could lower the dispersion in the matrix [38]. GNPs have strong Van der Waals forces between the adjacent planes of carbon rings, which potentially results in agglomeration, defects, or flaws in the PSU-GNP composites (Figure 4i) when compared with the CNT counterpart. Therefore, well-dispersed, thermally conductive fillers play a vital role to amplify phonon transport and hence to synergistically enhance thermal conductivity. 



Figure 4. FESEM micrographs of compositions: (a) pure PSU, (b) PSU- $1 w t \% C N T$, (c) PSU-3wt $\% C N T$ (d) PSU-5wt $\% C N T$, (e) PSU-10wt \%CNT, (f) PSU-1wt\%GNP, (g) PSU-3wt\%GNP, (h) PSU-5wt\%GNP, and (i) PSU-10wt \%GNP.

\subsection{Thermal Properties}

The thermal conductivity and effusivity of the PSU-CNT and PSU-GNP composites that resulted from the incorporation of fillers are shown in Figures 5 and 6, respectively. Whereas the setup for thermal conductivity and effusivity measurement was simply based on a sensor and processer, the setup for measuring the thermal properties used the modified transient plane source (MTPS) method. It requires only one sample to be placed on the disk-shaped sensor. The sensor also works as a heat source and simultaneously measures the transient effect of heat pulses to evaluate the thermal conductivity of the sample. 


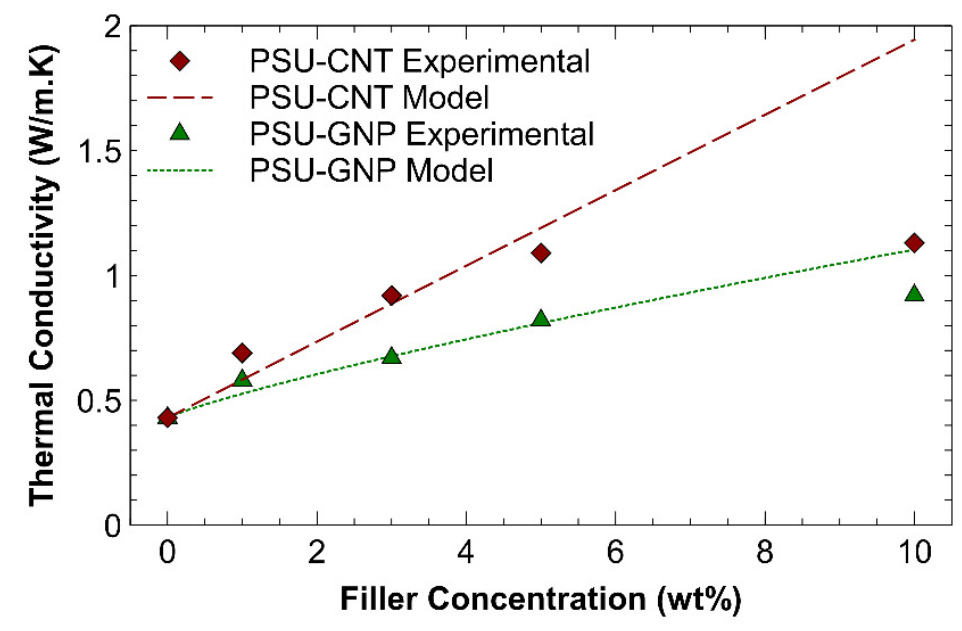

Figure 5. Effect of adding CNTs and GNPs on thermal conductivity of the resultant composites and their correlation with theoretical model.

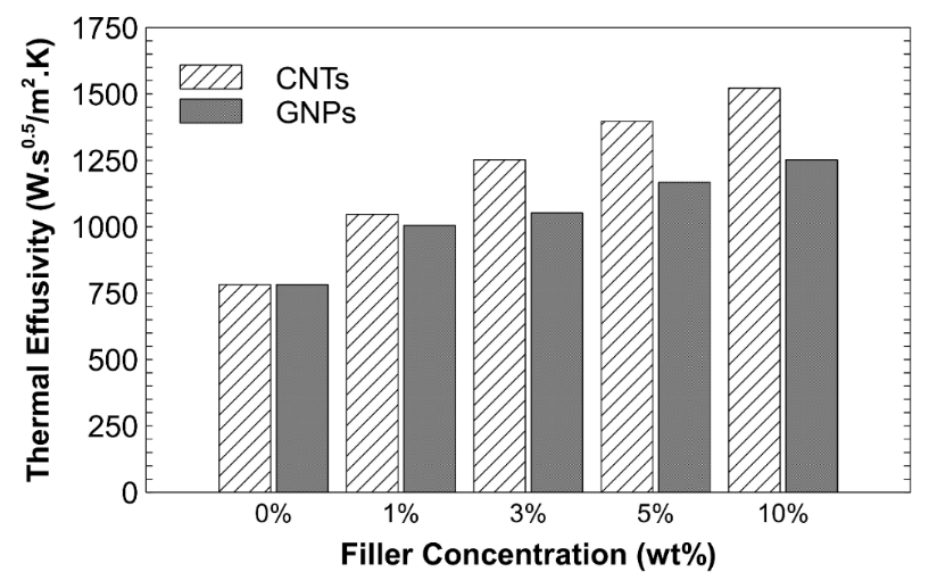

Figure 6. Effect of adding CNTs and GNPs on thermal effusivity of the resultant composites.

The experimental thermal conductivity results of the PSU-CNT and PSU-GNP composites were correlated with the theoretical model published by Raza et al. [46], which can be used for dilute concentrations of percolating single and hybrid fillers in polymer composites. It was observed that the results were close to the predictions of the model at lower concentrations of up to $5 \mathrm{wt} \%$. However, the deviations at $10 \mathrm{wt} \%$ can be attributed to the agglomeration among the nanoparticles and related defects, which were ignored by the theoretical model.

The thermal conductivity of the PSU-CNT and PSU-GNP nanocomposites varied as a function of the weight percentage and type of filler (CNTs or GNPs). The heat conduction or transmission of thermal energy requires interparticle connections. A strong interfacial interaction of particles with a combination of vibrations (i.e., phonons) and free electrons supports the fast transport of heat carriers (phonons and electrons). Phonon transport is the dominant mechanism in polymers, carbon, and their composites [47]. The mean free path for phonons in the polymer is lower (a few angstroms) compared to the mean free path for CNTs (hundreds of nanometres). Thermoplastics typically exhibit lower thermal conductivity and phonon transport inhibition because of their lower density, structural inhomogeneity, and mismatch in molecular vibrations. More importantly, their interfacial thermal resistance decreases the thermal conductivity of polymer nanocomposites [48], which has been predicted in developed models [49]. The fundamental transport and scattering of heat carriers (phonons and electrons) also depend on the bulk properties, whereas the properties of interfaces and finite dimensionality are vital issues in their 
applications [14]. The PSU-CNT composite with $10 \mathrm{wt} \%$ CNTs showed increased thermal conductivity compared to that of the PSU-GNP nanocomposite with $10 \mathrm{wt} \%$.

The polysulphone-CNT composite with $10 \mathrm{wt} \%$ CNTs shows an enhancement in thermal conductivity of $163 \%$, which is approximately $50 \%$ higher (increase) in comparison to the addition of $10 \mathrm{wt} \%$ graphene nano-platelets. This can be ascribed to the formation of an interconnecting network with strong coupling at the PSU-CNT interface in the case of CNTs, as predicted from the FESEM micrographs (Figure $4 \mathrm{~b}-\mathrm{e}$ ). The formation of the interconnecting network is much better at lower concentrations-that is, $1-5 \mathrm{wt} \%$ CNT/GNPs (Figure $4 \mathrm{~b}, \mathrm{c}, \mathrm{f}, \mathrm{g}$ ). The formation of an interconnecting/percolating network promotes heat flow. It reduces the phonon scattering at the interface between the reinforcements and polymers, which can improve the thermal transport in composites [41]. At higher reinforcement loading, interfacial thermal resistance obstructs further improvement in the thermal transport of charge carriers (phonons and electrons). The thermal properties of composites are a function of the volume fraction, aspect ratio, alignment, and adhesion interface condition between the particles and the matrix [50]. Nanofillers (such as CNTs and GNPs) with a high aspect ratio form a percolating network. These are promising candidates for high conductivity owing to their high-aspect-ratio nanofillers [33]. However, for graphene, there is a high probability of sheet-to-sheet contact even at comparatively low graphene loading because of the overlapping electronic clouds of neighbouring carbon atoms [38]. However, these conditions are well shown in Figure $4 \mathrm{f}-\mathrm{i}$; with better distribution, the conductivity can be improved to $114 \%$ compared to that of a neat (pristine) polymer. Thermal effusivity is a measure of the ability of a material to exchange thermal energy with its surroundings [51]. Table 2 shows the positive correlations between the amount of filler and the thermal effusivity.

Table 2. Thermal properties of PSU-CNT and PSU-GNP composite samples; the sample IDs are according to Table 1.

\begin{tabular}{|c|c|c|c|c|c|c|c|c|c|}
\hline \multicolumn{10}{|c|}{ Composition } \\
\hline Sample ID & 1 & 2 & 3 & 4 & 5 & 6 & 7 & 8 & 9 \\
\hline Composition & Pure PSU & $1 \% \mathrm{CNT}$ & $3 \% \mathrm{CNT}$ & $5 \% \mathrm{CNT}$ & $10 \% \mathrm{CNT}$ & $1 \%$ GNP & $3 \%$ GNP & $5 \%$ GNP & $10 \%$ GNP \\
\hline $\begin{array}{l}\text { Thermal Conductivity } \\
(\mathrm{W} / \mathrm{m} \cdot \mathrm{K})\end{array}$ & $0.43(3)$ & $0.69(3)$ & $0.92(5)$ & $1.09(1)$ & $1.13(7)$ & $0.58(6)$ & $0.67(3)$ & $0.82(2)$ & $0.92(3)$ \\
\hline $\begin{array}{c}\% \text { Increase in Thermal } \\
\text { Conductivity }\end{array}$ & 0 & 60 & 114 & 153 & 163 & 35 & 56 & 91 & 114 \\
\hline Thermal Effusivity & $782(3)$ & 1047(7) & $1252(6)$ & 1397(3) & $1522(2)$ & $1005(3)$ & 1052(5) & $1167(6)$ & $1252(8)$ \\
\hline $\begin{array}{l}\text { Thermal Expansion } \\
(\mathrm{ppm} / \mathrm{K})\end{array}$ & $60(4)$ & $57.6(6)$ & $49.8(3)$ & $45(5)$ & $38.4(1)$ & $58.2(2)$ & $54.6(3)$ & $50.4(1)$ & $45.6(5)$ \\
\hline $\begin{array}{l}\text { \% Reduction of } \\
\text { Thermal Expansion }\end{array}$ & 0 & 4 & 17 & 25 & 36 & 3 & 9 & 16 & 24 \\
\hline $\operatorname{Tg}\left({ }^{\circ} \mathrm{C}\right)$ & $190(2)$ & $210(2)$ & $230(6)$ & $245(8)$ & $250(7)$ & $205(4)$ & $220(3)$ & $235(4)$ & $240(2)$ \\
\hline
\end{tabular}

The measured coefficients of thermal expansion (CTE) of the samples are shown in Table 2 and Figure 7 as a function of the filler concentration.

Higher concentrations of CNTs and GNPs $(10 \mathrm{wt} \%)$ led to much lower CTE values than pristine PSU. The CTE values were reduced by $36 \%$ and $24 \%$ with the addition of CNTs and GNPs, respectively. The reduction in CTE is related to the bonding forces between the atoms and the available free volume in the polymer matrix. With the increase in the filler concentration, the bonding forces of the composite structure increased, and the free volume decreased. Hence, the expansion caused by the temperature change was restrained, resulting in a lower CTE (which is higher at a $10 \mathrm{wt} \%$ loading, as shown in Figure $4 \mathrm{a}-\mathrm{i}$ ). Hence, the high concentration of fillers contracts the space available for the expansion of the polymer and ultimately reduces the CTE of the composites (Table 2). The second-order phase transition phenomenon, which is known as the $\mathrm{Tg}$, is common in polymeric and noncrystalline materials. The material transforms from a brittle, crystalline, semicrystalline solid into an elastic, amorphous solid [52]. The Tg values of the pristine PSU and its composites are shown in Table 2 and Figure 8. 


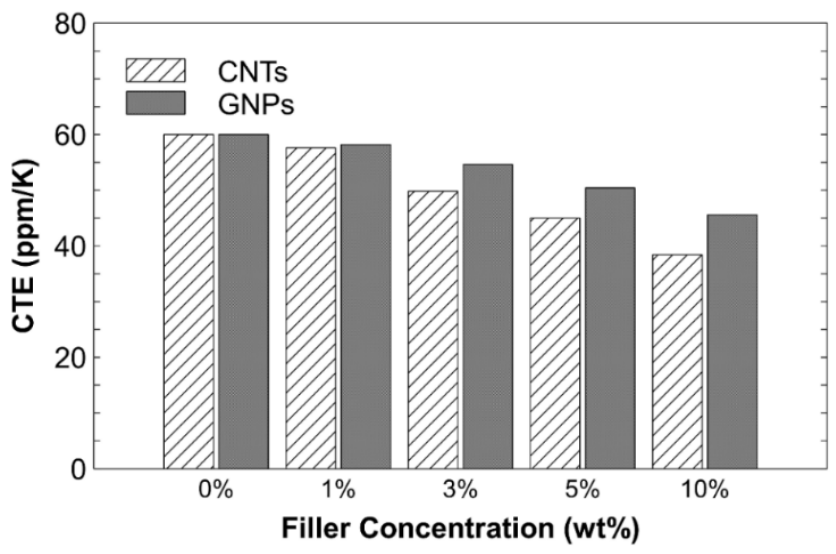

Figure 7. Effect of adding CNTs and GNPs on the coefficient of thermal expansion of the resultant composites.

The pristine PSU exhibited a $\mathrm{Tg}$ of $190{ }^{\circ} \mathrm{C}$. After the addition of CNTs, the $\mathrm{Tg}$ of the nanocomposites was shifted to a higher temperature, which showed the improved thermal stability (to a certain extent) of the composites. In this study, after the addition of the reinforcements, the $\mathrm{Tg}$ increased from $190{ }^{\circ} \mathrm{C}$ (for pristine PSU) to $250{ }^{\circ} \mathrm{C}$ (with a $10 \mathrm{wt} \%$ addition of CNTs). The shift in the $\mathrm{Tg}$ to a higher temperature can be attributed to the close affinity between the matrix and reinforcements owing to intermolecular hydrogen bonding at the interface [53]. The $\mathrm{T} g$ value increases with an increase in the weight fraction of fillers in a polymer matrix, which is credited to the improved compatibility and interaction between the matrix and the filler. However, it was observed that with the addition of either type of filler (CNTs or GNPs) from $5 \mathrm{wt} \%$ to $10 \mathrm{wt} \%$, there was no significant increase in $\mathrm{T} g$. The $\mathrm{T} g$ value depends on the free volume and interface connections between the fillers and the matrix. Therefore, compositions with better affinity to fillers show higher $\mathrm{Tg}$ values owing to less molecular motion and the reduced free volume of the polymer molecules [27,28]. Better distribution and cross-linking of embedded reinforcements in the polymer matrix, as shown in Figure $4 \mathrm{~b}-\mathrm{i}$, reduce the motions of polymer molecules, resulting in an increase in $\mathrm{Tg}$ (Figure 8 ) and a reduction in the thermal expansion (Figure 7). In addition to this, another critical observation was that there was no significant improvement in the observed thermal properties from 5 to $10 \mathrm{wt} \%$ fillers (Table 2). Hence, based on the experimental observations, it is recommended that simple fabrication techniques with the correct selection and combination of fillers in the polymer matrix can aid in the design of polymer composites at an economical rate for various industrial applications.

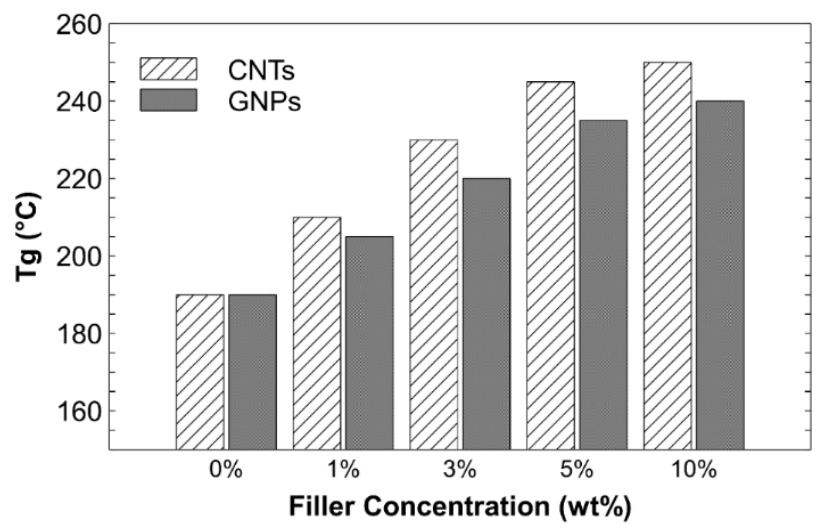

Figure 8. Effect of adding CNTs and GNPs on glass transition temperatures ( $\mathrm{Tg}$ ) of composites. 


\section{Conclusions}

Polysulphone (PSU) nanocomposites with carbon nanotubes (CNTs) and graphene nanoplatelets (GNPs) with the addition of $1-10 \%$ weight percentage were prepared using the solution casting technique. The FESEM micrographs showed reasonable dispersion and established solid interfacial bonding between the PSU and both types of nanofillers (CNTs and GNPs). Notably, the developed composites (PSU-CNT and PSU-GNP) showed improved thermal properties such as stability, conductivity, and expansion upon the addition of CNTs and GNPs from 1 to $10 \mathrm{wt} \%$. The thermal conductivity and glass transition temperature $(\mathrm{Tg})$ of $10 \mathrm{wt} \%$ of PSU-CNT were $1.13 \mathrm{~W} / \mathrm{m} \cdot \mathrm{K}$ and $250^{\circ} \mathrm{C}$, respectively, which were better than the $10 \% \mathrm{wt}$ of PSU-GNPs $\left(0.92 \mathrm{~W} / \mathrm{m} \cdot \mathrm{K}\right.$ and $\left.240{ }^{\circ} \mathrm{C}\right)$, and there was an increase of approximately $163 \%$ compared to pure PSU. In comparison, the composite with $10 \mathrm{wt} \%$ CNTs in PSU possessed a more favourable combination of three-dimensional interconnected microstructure and thermal properties for thermal applications. These results highlight the significance of the type, composition, and distribution of the nanofiller in the microstructural and thermal characteristics of the polymer nanocomposites. Hence, this study paves the way towards the design and development of promising polymer composites with beneficial thermal properties to be used in niche applications.

Author Contributions: Conceptualization; A.S.H., M.A.E.; Methodology; A.S.H., M.A.E.; Validation; A.S.H., S.A., H.M.I., K.R., M.A.E.; Formal analysis; A.S.H., M.A.E., H.M.I.; Investigation; A.S.H., S.A., H.M.I., K.R., T.N.B., M.A.E., M.S.T.; Resources; A.S.H., H.M.I., K.R., T.N.B., M.A.E., M.S.T., S.A.; Data curation; A.S.H., S.A., H.M.I.; Writing—original draft preparation; H.M.I., A.S.H.; Writing—review and editing; A.S.H., S.A., K.R., T.N.B., M.A.E., M.S.T.; Visualization; A.S.H., M.A.E., H.M.I.; Supervision; A.S.H.; Project administration; A.S.H., H.M.I., K.R., M.A.E.; Funding acquisition; A.S.H. All authors have read and agreed to the published version of the manuscript.

Funding: This research was funded by the Deanship of Scientific Research (DSR) at King Fahd University of Petroleum \& Minerals (KFUPM).

Institutional Review Board Statement: Not applicable.

Informed Consent Statement: Not applicable.

Data Availability Statement: Not applicable.

Acknowledgments: The authors would like to acknowledge the support provided by the Deanship of Scientific Research (DSR) at King Fahd University of Petroleum and Minerals (KFUPM), Dhahran, Saudi Arabia.

Conflicts of Interest: The authors declare no conflict of interest.

\section{References}

1. Chen, H.; Ginzburg, V.V.; Yang, J.; Yang, Y.; Liu, W.; Huang, Y.; Du, L.; Chen, B. Thermal conductivity of polymer-based composites: Fundamentals and applications. Prog. Polym. Sci. 2016, 59, 41-85. [CrossRef]

2. Camargo, P.H.C.; Satyanarayana, K.G.; Wypych, F. Nanocomposites: Synthesis, structure, properties and new application opportunities. Mater. Res. 2009, 12, 1-39. [CrossRef]

3. Yang, Y. Thermal conductivity. In Physical Properties of Polymers Handbook, 2nd ed.; Mark, J.E., Ed.; Springer: New York, NY, USA, 2007; pp. 155-163.

4. Hussain, A.R.J.; Alahyari, A.A.; Eastman, S.A.; Thibaud-Erkey, C.; Johnston, S.; Sobkowicz, M.J. Review of polymers for heat exchanger applications: Factors concerning thermal conductivity. Appl. Therm. Eng. 2017, 113, 1118-1127. [CrossRef]

5. Saba, N.; Jawaid, M. A review on thermomechanical properties of polymers and fibers reinforced polymer composites. J. Ind. Eng. Chem. 2018, 67, 1-11. [CrossRef]

6. Davis, A. Thermal stability of polysulphone. Die Makromol. Chem. Macromol. Chem. Phys. 1969, 128, 242-251. [CrossRef]

7. Bose, S.; Kuila, T.; Nguyen, T.X.H.; Kim, N.H.; Lau, K.-T.; Lee, J.H. Polymer membranes for high temperature proton exchange membrane fuel cell: Recent advances and challenges. Prog. Polym. Sci. 2011, 36, 813-843. [CrossRef]

8. Sur, G.; Sun, H.; Lyu, S.; Mark, J. Synthesis, structure, mechanical properties, and thermal stability of some polysulfone/organoclay nanocomposites. Polymer 2001, 42, 9783-9789. [CrossRef]

9. Chlopek, J.; Rosol, P.; Morawska-Chochol, A. Durability of polymer-ceramics composite implants determined in creep tests. Compos. Sci. Technol. 2006, 66, 1615-1622. [CrossRef] 
10. Sohail, O.B.; Sreekumar, P.; De, S.; Jabarullah Khan, M.; Hakeem, A.; Alshaiban, A.A.; Al-Harthi, M.A. Thermal effect of ceramic nanofiller aluminium nitride on polyethylene properties. J. Nanomater. 2012, 2012, 87. [CrossRef]

11. Lu, X.; Xu, G. Thermally conductive polymer composites for electronic packaging. J. Appl. Polym. Sci. 1997, 65, 2733-2738. [CrossRef]

12. Raza, K.; Akhtar, S.S.; Arif, A.F.M.; Hakeem, A.S. Design of a Composite Encapsulation for Concentrated Photovoltaic Systems With Improved Performance. ASME Int. Mech. Eng. Congr. Expo. 2019. [CrossRef]

13. Raza, K.; Akhtar, S.S.; Arif, A.F.M.; Hakeem, A.S. Computational design and development of high-performance polymercomposites as new encapsulant material for concentrated PV modules. Sci. Rep. 2020, 10, 1-14. [CrossRef] [PubMed]

14. Schelling, P.K.; Shi, L.; Goodson, E. Managing heat for electronics. Mater. Today 2005, 8, 30-35. [CrossRef]

15. Tyagi, M.; Tyagi, D. Polymer nanocomposites and their applications in electronics industry. Int. J. Electron. Electr. Eng. 2014, 7, 603-608.

16. Wong, C.; Bollampally, R.S. Thermal conductivity, elastic modulus, and coefficient of thermal expansion of polymer composites filled with ceramic particles for electronic packaging. J. Appl. Polym. Sci. 1999, 74, 3396-3403. [CrossRef]

17. Khan, M.Y.; Khan, A.; Elsharif, A.M.; Helal, A.; Yamani, Z.; Hakeem, A.S. Mixed dimensional nanostructure (UiO66 decorated MWCNT) as nanofiller in MMMs for enhanced $\mathrm{CO}_{2} / \mathrm{CH}_{4}$ separation. Chem. A Eur. J. 2021, 27, 11132-11140. [CrossRef] [PubMed]

18. Yu, J.; Cennini, G. Improving thermal conductivity of polymer composites in embedded LEDs systems. Microelectron. J. 2014, 45, 1829-1833. [CrossRef]

19. Zahir, M.H.; Helal, A.; Hakeem, A.S. Hybrid polyMOF materials prepared by combining an organic polymer with a MOF and their application for solar thermal energy storage. Energy Fuels 2021, 35, 10199-10209. [CrossRef]

20. Tessema, A.; Zhao, D.; Moll, J.; Xu, S.; Yang, R.; Li, C.; Kumar, S.K.; Kidane, A. Effect of filler loading, geometry, dispersion and temperature on thermal conductivity of polymer nanocomposites. Polym. Test. 2017, 57, 101-106. [CrossRef]

21. Gu, J.; Meng, X.; Tang, Y.; Li, Y.; Zhuang, Q.; Kong, J. Hexagonal boron nitride/polymethyl-vinyl siloxane rubber dielectric thermally conductive composites with ideal thermal stabilities. Compos. Part A Appl. Sci. Manuf. 2017, 92, 27-32. [CrossRef]

22. Weidenfeller, B.; Höfer, M.; Schilling, F.R. Thermal conductivity, thermal diffusivity, and specific heat capacity of particle filled polypropylene. Compos. Part A Appl. Sci. Manuf. 2004, 35, 423-429. [CrossRef]

23. Yang, Y.; Wang, P.; Zheng, Q. Preparation and properties of polysulfone/ $\mathrm{TiO}_{2}$ composite ultrafiltration membranes. J. Polym. Sci. Part B Polym. Phys. 2006, 44, 879-887. [CrossRef]

24. Weidenfeller, B.; Höfer, M.; Schilling, F. Thermal and electrical properties of magnetite filled polymers. Compos. Part A Appl. Sci. Manuf. 2002, 33, 1041-1053. [CrossRef]

25. Zhao, Y.-H.; Zhang, Y.-F.; Bai, S.-L.; Yuan, X.-W. Carbon fibre/graphene foam/polymer composites with enhanced mechanical and thermal properties. Compos. Part B Eng. 2016, 94, 102-108. [CrossRef]

26. Yang, S.-Y.; Lin, W.-N.; Huang, Y.-L.; Tien, H.-W.; Wang, J.-Y.; Ma, C.-C.M.; Li, S.-M.; Wang, Y.-S. Synergetic effects of graphene platelets and carbon nanotubes on the mechanical and thermal properties of epoxy composites. Carbon 2011, 49, 793-803. [CrossRef]

27. Hong, J.; Lee, J.; Jung, D.; Shim, S.E. Thermal and electrical conduction behavior of alumina and multiwalled carbon nanotube incorporated poly (dimethyl siloxane). Thermochim. Acta 2011, 512, 34-39. [CrossRef]

28. Takenaka, K.; Ichigo, M. Thermal expansion adjustable polymer matrix composites with giant negative thermal expansion filler. Compos. Sci. Technol. 2014, 104, 47-51. [CrossRef]

29. Takenaka, K. Negative thermal expansion materials: Technological key for control of thermal expansion. Sci. Technol. Adv. Mater. 2012, 13, 013001. [CrossRef]

30. Hu, N.; Jia, B.; Arai, M.; Yan, C.; Li, J.; Liu, Y.; Atobe, S.; Fukunaga, H. Prediction of thermal expansion properties of carbon nanotubes using molecular dynamics simulations. Comput. Mater. Sci. 2012, 54, 249-254.

31. Hu, C.; Li, Z.; Wang, Y.; Gao, J.; Dai, K.; Zheng, G.; Liu, C.; Shen, C.; Song, H.; Guo, Z. Comparative assessment of the strainsensing behaviors of polylactic acid nanocomposites: Reduced graphene oxide or carbon nanotubes. J. Mater. Chem. C 2017, 5, 2318-2328. [CrossRef]

32. Balandin, A.A.; Ghosh, S.; Bao, W.; Calizo, I.; Teweldebrhan, D.; Miao, F.; Lau, C.N. Superior thermal conductivity of single-layer graphene. Nano Lett. 2008, 8, 902-907. [CrossRef]

33. Han, Z.; Fina, A. Thermal conductivity of carbon nanotubes and their polymer nanocomposites: A review. Prog. Polym. Sci. 2011, 36, 914-944. [CrossRef]

34. Martin-Gallego, M.; Bernal, M.; Hernandez, M.; Verdejo, R.; López-Manchado, M.A. Comparison of filler percolation and mechanical properties in graphene and carbon nanotubes filled epoxy nanocomposites. Eur. Polym. J. 2013, 49, 1347-1353. [CrossRef]

35. Díez-Pascual, A.M.; Ashrafi, B.; Naffakh, M.; González-Domínguez, J.M.; Johnston, A.; Simard, B.; Martinez, M.T.; Gómez-Fatou, M.A. Influence of carbon nanotubes on the thermal, electrical and mechanical properties of poly (ether ether ketone)/glass fiber laminates. Carbon 2011, 49, 2817-2833. [CrossRef]

36. Kim, H.S.; Jang, J.-U.; Yu, J.; Kim, S.Y. Thermal conductivity of polymer composites based on the length of multi-walled carbon nanotubes. Compos. Part B Eng. 2015, 79, 505-512. [CrossRef]

37. Ma, P.-C.; Siddiqui, N.A.; Marom, G.; Kim, J.-K. Dispersion and functionalization of carbon nanotubes for polymer-based nanocomposites: A review. Compos. Part A Appl. Sci. Manuf. 2010, 41, 1345-1367. [CrossRef] 
38. Kotov, N.A. Materials science: Carbon sheet solutions. Nature 2006, 442, 254. [CrossRef]

39. Zhang, Y.-F.; Zhao, Y.-H.; Bai, S.-L.; Yuan, X. Numerical simulation of thermal conductivity of graphene filled polymer composites. Compos. Part B Eng. 2016, 106, 324-331. [CrossRef]

40. Kuilla, T.; Bhadra, S.; Yao, D.; Kim, N.H.; Bose, S.; Lee, J.H. Recent advances in graphene based polymer composites. Prog. Polym. Sci. 2010, 35, 1350-1375. [CrossRef]

41. Liao, Q.; Liu, Z.; Liu, W.; Deng, C.; Yang, N. Extremely high thermal conductivity of aligned carbon nanotube-polyethylene composites. Sci. Rep. 2015, 5, 16543. [CrossRef] [PubMed]

42. Du, J.; Bai, J.; Cheng, H. The present status and key problems of carbon nanotube based polymer composites. Express Polym. Lett. 2007, 1, 253-273. [CrossRef]

43. Ionita, M.; Pandele, A.M.; Crica, L.; Pilan, L. Improving the thermal and mechanical properties of polysulfone by incorporation of graphene oxide. Compos. Part B Eng. 2014, 59, 133-139. [CrossRef]

44. Vidakis, N.; Petousis, M.; Tzounis, L.; Velidakis, E.; Mountakis, N.; Grammatikos, S.A. Polyamide 12/multiwalled carbon nanotube and carbon black nanocomposites manufactured by 3D printing fused filament fabrication: A comparison of the electrical, thermoelectric, and mechanical properties. C 2021, 7, 38.

45. Tzounis, L.; Pegel, S.; Zafeiropoulos, N.E.; Avgeropoulos, A.; Paipetis, A.S.; Stamm, M. Shear alignment of a poly (styrenebutadiene-styrene) triblock copolymer/MWCNT nanocomposite. Polymer 2017, 131, 1-9. [CrossRef]

46. Raza, K.; Siddiqui, M.U.; Arif, A.F.M.; Akhtar, S.S.; Hakeem, A.S. Design and development of thermally conductive hybrid nano-composites in polysulfone matrix. Polym. Compos. 2019, 40, 1419-1432. [CrossRef]

47. Balandin, A.A. Thermal properties of graphene and nanostructured carbon materials. Nat. Mater. 2011, 10, 569. [CrossRef] [PubMed]

48. Zabihi, Z.; Araghi, H. Effect of functional groups on thermal conductivity of graphene/paraffin nanocomposite. Phys. Lett. A 2016, 380, 3828-3831. [CrossRef]

49. Nan, C.-W.; Liu, G.; Lin, Y.; Li, M. Interface effect on thermal conductivity of carbon nanotube composites. Appl. Phys. Lett. 2004, 85, 3549-3551. [CrossRef]

50. Shenogin, S.; Xue, L.; Ozisik, R.; Keblinski, P.; Cahill, D.G. Role of thermal boundary resistance on the heat flow in carbon-nanotube composites. J. Appl. Phys. 2004, 95, 8136-8144. [CrossRef]

51. Kemaloglu, S.; Ozkoc, G.; Aytac, A. Properties of thermally conductive micro and nano size boron nitride reinforced silicon rubber composites. Thermochim. Acta 2010, 499, 40-47. [CrossRef]

52. Verdejo, R.; Bernal, M.M.; Romasanta, L.J.; Lopez-Manchado, M.A. Graphene filled polymer nanocomposites. J. Mater. Chem. 2011, 21, 3301-3310. [CrossRef]

53. Nayak, L.; Rahaman, M.; Khastgir, D.; Chaki, T. Thermal and electrical properties of carbon nanotubes based polysulfone nanocomposites. Polym. Bull. 2011, 67, 1029. [CrossRef] 